\title{
Drone delivery efficiency, challenges, and potential in Oman
}

\section{during COVID-19}

\author{
Reem Khamis Al-Ghaithi ${ }^{1}$, Zouhaier Slimi ${ }^{2}$ and Abdelsalam Adam Hamid ${ }^{3}$ \\ ${ }^{1}$ Logistics and Transport Management department, International Maritime College Oman \\ ${ }^{2}$ English language - lecturer, Foundation, International Maritime College Oman \\ ${ }^{3}$ Assistant Professor, Logistics and Transport Management department, International Maritime College Oman
}

\begin{abstract}
This article provides a unique snapshot of the efficiency of drone delivery services in Oman. The study aims to investigate the performance of drone delivery in Oman during the coronavirus. Therefore, it highlighted the challenges that drone delivery may face in Oman during the COVID-19. One of the significant objectives of conducting this research study is to predict drone delivery services in Oman. The scope of the study's limits in the drone delivery industry during and post COVID-19 crisis in Oman. This paperwork used a qualitative approach to gather needed data. The researcher conducted semistructured interviews to collect information from different participants. Findings reveal that Oman is still at the beginning stage of implementing drone delivery services during the coronavirus crisis, requiring a wise mindset, tactical plans, and penitent to grow the drone industry in Oman rapidly. The findings vindicate that Oman did successful experiments for conveying parcels via drones, which is a good prediction for drone appliances in Oman. The results predicted the challenges that drone delivery services may face in Oman: government limitations, technical challenges, privacy challenges, and safety challenges. Therefore, more research in this domain is needed to comprehensively understand better drone delivery services in Oman post the coronavirus era.
\end{abstract}

Keywords: COVID-19, Delivery services, Drone, GPS, UAV 


\section{Introduction}

Recently, the use of drones for commercial transportation purposes is poised to be a new industry. Several companies around the world imagine the globe in which everyday commodities will deliver through drones. Various countries worldwide, such as Oman, leverage state of the art digital technologies to build smart cities (Lai, Liu and Tsay, 2020). This chapter paves the path for the entire topic of the research. It will introduce part of the research study, beginning with the research background and problem statement, to discuss research significance, research justification, research limitation, and the research structure.

\subsection{Background of the research}

In the era of the internet and technologies, the logistics and transportation industry continuesto develop. Only quick, modern and automated transportation means can meet the growth of logistics demand. Drones have these distinctive characteristics. Drones play a pivotal role in smart cities for transporting parcel packages. Drones are commonly known as Unmanned Aerial Vehicles (UAVs), Unmanned Aircraft (UA), Remotely Operated Aircraft (ROA), and Remotely Piloted Aircraft (RPA) (Scott and Scott, 2018). The UAVs or drones refer to flying devices monitored remotely through a person or a computer to deliver parcels to customers'doors within a short time. These UAVs ${ }^{4}$ are pre-programmed to fly autonomously on pre-identified routes (EUCHI, 2020). Thanks to today's computing, sensing and robotic technologies, which force the drones'industry's fast growth and implement another means of transportation. To keep pace with the latest technologies, build smart cities, and optimise the supply chain, several countries such as Oman are turned to adapt to the fourth industrial revolution, including using drones to deliver goods.
As the novel COVID $-19^{5}$ continues its onslaught all over the globe, the world is reeling under the weight of collapsing economies and accumulating losses. On the other hand, the coronavirus outbreak forces the world to emerge new technological approaches to deal with the impact of the COVID-19 crisis. Drones and UAVs have been at the forefront (Chamola et al., 2020). According to Euchi (2020), specialising in Information Systems and Production Management, digital technologies, including drones, play a crucial role in enhancing public health response to the COVID-19 crisis (EUCHI, 2020).

At the aggregate level, logistics and transportation services providers benefit from implementing dronesto deliver considering the coronavirus pandemic. The researcher realised that it is beneficial to study the efficiency of drone delivery services in Oman. It enables the researcher to find proper solutions to develop this alternative modality in Oman shortly.

\subsection{Problem statement}

With the drones' delivery industry's growth during the COVID-19 crisis, several companies worldwide imagine a global in which daily commodities will be transported via drones through the air. This leads to an expanding drone delivery market shortly. Here in Oman, Oman's vision 2040 aims to promote and adapt the fourth industrial revolution and invest in the logistics sector to build smart cities (Oman Vision 2040, 2020). This leads Oman to be a strong competitor and reinforce its position as a logistics hub. The successful growth in future large-scale drones' delivery could revolutionarily transform the industry, replacing thousands of fuel truck deliveries, road congestion, and central delivery hub with drones, miniature aircraft, airlift, mobile seats, and door-to-door delivery. This transformation may maximise road safety, minimise road traffic, and having accessibility to unreachable areas with poor road infrastructure (Frachtenberg, 2019). However, during the 
pandemic, several challenges drone delivery may face in Oman. For example, government limitations, technical issues, and an increase in the unemployment rate. In the future, drone delivery services in Oman will be used to deliver different types of commodities such as food, human aid, and postal delivery.Fewer researches focus on the expectation of drone delivery post-COVID-19 era. Moreover, there is no Article focuses on drone delivery services in Oman during the coronavirus crisis.

\section{Research gap}

Commonly, most of the previous studies highlighted the efficiency of drone delivery services and market growth. A crucial review of drone delivery services in Oman and other countries helped achieve the first research objective. Several researchers close their attention to studying the efficiency of drone services in the fight against the coronavirus crisis. Whilst various researchers study the chance of commercial drones to serve multiple fields in the future. Besides, many journal articles focus on the challenges drone delivery may face during the COVID-19 pandemic. Nevertheless, fewer researches focus on the expectation of drone delivery post-COVID-19 era. Furthermore, more occasional research articles focus on drone delivery in Oman and its efficiency during the coronavirus crisis.

The researcher found it worthy of studying the efficiency of drone delivery services in Oman to bring new ideas, build smart cities and optimise the supply chain. In the researcher's opinion, focusing on this topic is essential as Oman recently adapted to the fourth industrial revolution and built intelligent cities. The core objective behind researching this topic is to develop new ideas and strategies for logistics and transportation companies willing to use drone delivery services in Oman soon.

\subsection{Research justification}

Currently, drones' usage for delivery purposes is increased, which leads to the growth of the drone market. Several countries, such as Oman, aim to build smart cities to utilise alternative drones for transporting commodities. During the COVID-19 crisis, the reliance on drone delivery increased where several researchers consider the COVID-19 pandemic as the golden era for the drone delivery revolution (Hwang, Kim and Kim, 2020). The researcher desires to improve her knowledge and investigate the drone delivery revolution in the Oman post and COVID-1the 9 crisis. The researcher has the curiosity and the drive to suggest solutions to fight a real-world problem and add something positive to her country. This research grants the researcher's opportunity to express her recommendations to beat the challenges that drones' delivery in Oman may face during the COVID-19 crisis.

This research contributing to the existing research contribution by examining the efficiency of drone on delivery during covid19in sultanate of Oman. the study extending the context of drone in logistics, and delivery in the context on GCC and sultanate Oman. moreover, this study contributing by giving valuable insights to logistics companies and other business activities.

this research, is structured based onfive main sections. The first section includes introduction, background, problem statement .section two comprises various arguments from different research articles regarding the efficiency of drone delivery services in Oman during the coronavirus era. Besides, it contains different views from several academic researchers about the challenges that drone delivery may face and the future of drone delivery services post the COVID-19 crisis. section three clarifies the research methodology and data collection, which fit with the research topic. The methodology section consists of choosing the inductive approach, qualitative research and interviewing tools. section four demonstrates and analyses the findings concerning the efficiency of drone delivery services in Oman during and post the coronavirus pandemic. The last sectionsummaries the researcher's findings and ends with providing recommendations. 


\subsection{Scope of research}

As the utilization of drones' delivery increases during COVID-19, the revolution of drone delivery is shortly estimated to grow. However, there are various challenges during COVID-19 for using drones for transportation purposes in Oman. Nevertheless, in the future, several opportunities will be available for drone delivery services in Oman, which will make the drone delivery service more efficient. This study seeks to investigate the vision and revolution of drone delivery services in Oman during and after COVID-19. The research study intended to highlight the efficiency and challenges for drone delivery services in Oman during and after the COVID-19 pandemic. The scope of the study's limits in the drone delivery industry during and post COVID-19 crisis. Correspondingly, the study area for this research is Oman. With its vision 2040, which targets the fourth industrial revolution's adaptation and the investment in logistics and transportation sectors to build smart cities, Oman is enabled to keep its competitive spot as a logistics hub.

\section{Literature review}

Currently, UAVs or drones are one of the rapidgrowing sectors. Nowadays, the applications of drones are widely increasing in diverse aspects due to their significant values. Hong Jiang and Xinhui Ren (2020) believe that commercial drones become efficient means of delivery with the popularisation of drones. They mentioned that commercial drones are fast, reliable, sustainable, and cost-efficient than other transportation modalities (Jiang and Ren, 2020). There is a share of consistent evidence that utilising technologies such as drones delivery enhance transportation efficiency, avoid the impact of congestion and make the delivery path more diversified. Thus, commercial drones become an essential part of the intelligent logistics supply chain. It brings commodities, people and places closer, easier and faster. Here in Oman, Oman's vision 2040 aims to adapt and promote the fourth industrial revolution and invest in the logistics industry for building smart cities. Therefore, Oman will keep its competitive position as a logistics hub (Oman Vision 2040, 2020).

\subsection{The efficiency of drone delivery in Oman during COVID-19}

Recently, global is witnessing the emergence of a new era in the automotive industry. Lately, the usage of drones for commercial purposes receives much attention. Nowadays, Oman Logistics Centre (OLC) and ASYAD utilise drones for parcel delivery and inventory stock counting. According to the ASYAD (2020), since the beginning of the COVID-19 pandemic, the OLC and other drone companies in Oman start to invest various resources for testing drone delivery services. They have been lobbying to apply these services (ASYAD, 2020). The first experiment of conveying goods via drones in Oman was in Nizwa. The Nizwa drones transported a parcel weighing approximately about $1.5 \mathrm{~kg}$ around three Kilometers within four minutes. As a result, it matches the best global drone delivery speed (ASYAD, 2020). Furth9+8more, the Muscat drone conveyed a parcel weighing almost about $1.5 \mathrm{Kg}$ in less than four and a half minutes over three Kilometers(ASYAD, 2020). Both deliveries showed magnificent evidence for the rapid growth of drone delivery services in Oman by the near future. From the researcher's point of view, the increase in drone delivery services in Oman helps to enhance logistics operations' efficiency, minimise cost, and maximise productivity.

Vyshnave, Elysee, Patrick and Lorie (2020) theorise that drones' delivery holds a great promise to succour infectious diseases control and respond to public health emergencies(Jeyabalan et al., 2020). Several studies mentioned that drone operators worldwide started to cater to the new demand due to the COVID-19 crisis. They transport medical supplies, groceries and other necessary goods via drones (OECD, 2020; EUCHI, 2020; Jeyabalan et al., 2020). A systematic review by the International Transport Forum confirmed that since the coronavirus outbreak, drones used to transport daily necessities and medical 
supplies to avoid human interaction, monitor social distances and confined citizens (OECD, 2020). Throughout the literature, drones facilitate impractical travels, whether simply being able to fast deliver medicines and essentials to humans who need them, or emergency, where the saved minutes means saving lives.

\subsubsection{The efficiency of drone delivery during COVID-19 in the healthcare aspect}

Drone technology extensively utilised in the healthcare industry to combat the COVID-19 pandemic. Arguably, considering COVID-19, drone applications are used chiefly in the healthcare aspect as human lives are at stake. Previous studies emphasised that drone applications in healthcare comprise the delivery of medicines, blood samples, lab samples, vaccines, defibrillators, and other medical supplies (Scott and Scott, 2018; Hii, Courtney and Royall, 2019; UNICEF, 2020;Jeyabalan et al., 2020). Mohsen Guizani and other researchers who are members of the Qatar National Research Fund mentioned in their article that in September 2019, researchers from the National University of Ireland tested a drone to transport diabetes medicines (Chamola et al., 2020). Micelle Hii, Patrick Courtney and Paul Royall from King's College London conducted another experiment to test insulin delivery via drone to remote areas(Hii, Courtney and Royall, 2019). Both successful experiments provided evidence to the world on how UAVs can deliver healthcare supplies reliably. According to the published article by the ITF $^{1}$, considering the COVID-19 crisis, about eighteen countries utilised drone technology for transportation purposes, including Oman. It also highlighted that China was the first country that operates the drone for delivery services. It successfully delivered medical supplies and test samples from a local hospital in Zhejiang to a neighbouring disease monitor centre (OECD, 2020). More recent evidence cited in the $\mathrm{ITF}^{6}$ article, wherein the USA, after devastating the impact of COVID-
19 pandemic, US agencies took various steps to apply the utilisation of drones for delivery services. A zip line was established as an active medical supply transportation network to deliver urgent medicines directly to human's doorsteps (OECD, 2020). Therefore, the utilisation of drones in infected countries helps to minimise human interaction. From the researcher's perspective, the idea of utilising a drone to deliver healthcare supplies considering the COVID-19 pandemic helps to reduce the exposure to infection, reduce transportation time, and decrease the risk of transmission.

\subsubsection{The efficiency of drone}

\section{delivery during COVID-19 in the}

\section{food field}

Apart from being a quick and safe approach to deliver medical supplies, commercial drones facilitate the transportation of foods and necessary goods considering the COVID-19 pandemic. Jinsoo, Dohyung and Jjinkyung, who specialise in hospitality and tourism management, hypothesised that after the outbreak of COVID-19, people tended to prefer home delivery services to eat or shop outside. They theorised that drone delivery services are attracting attention to transport foods and other goods. They use drones to deliver foods because the drone is contactless services and provide delivery without face-to-face encounters(Hwang, Kim and Kim, 2020). Several recent studies pointed out drones' application to deliver food and other necessary commodities in various countries during the COVID-19 outbreak. International Transport Forum stated in its recent article that in China, JD.com, a Chinese e-commerce company, launched a group of drones to distribute food. This implementation of drones replaced onehour delivery times with a flight of almost 10 minutes (OECD, 2020). Jinsoo (2020) and other researchers mentioned in their journal article that in the USA, Uber, which is a delivery company, tested drones in the food and groceries delivery aspect during the COVID-19 crisis. Uber estimates to start food transportation via drone in San Diego at the beginning of 2021. 
In contrast, the customers will receive food in front of their door within five to thirty minutes (Hwang, Kim and Kim, 2020). Insoo Hwang, Insan Kim and Muhammad Gulzar, who specialise in transportation and tourism, highlighted in their journal article that Costa Coffee in Dubai utilises drones to deliver coffeewithout human interaction to control social distancing (Hwang, Kim and Gulzar, 2020). These drone applications in various countries prove how UAVs or drones can respond to public health emergencies. The researcher strongly agrees with the idea of using the drone for delivering food and other goods where this let the whole world understands the capability and ability of drones to bring positive change and facilitate commodities movement considering the COVID-19 outbreak.

\subsection{Challenges ofdronesin Oman during COVID-19}

Hailong Huang and Andrey Savkin, who are specialised in electrical engineering and telecommunication, postulate that although parcel delivery via drones brings several attractive advantages, its application is limited due to several challenges. These challenges could prevent drones from transporting goods to the far customer (Huang and Savkin, 2020). Mohsen Guizani and other academic researchers theorise that despite the various benefits drones provide in response to world crises like the COVID-19 pandemic, the utilisation of drones confronts certain limitations and challenges. Until then, several countries worldwide do not yet adapt drones to fight against the COVID-19 crisis (Chamola et al., 2020). The researcher finds many journal articles close their attention to the drone's challenges considering the COVID-19 outbreak. The researcher divides the challenges into three significant challenges: technical challenges, legislation challenges, and safety and privacy challenges.

\subsubsection{Technical challenges that drone delivery may face}

The first challenges that drones may face during the COVID-19 pandemic are technical. Several studies mentioned that the significant technical challenges include limited battery life, short coverable distance and limited payload capacity (Lai, Liu and Tsay, 2020; Alwateer and Loke, 2020; Hii, Courtney and Royall, 2019). Suttinee Sawdsitang and other researchers who are specialised in the field of computer science and engineering at Nanyang University confirmed in their research study that customers who are located far from the serving area, the supplier cannot utilise drones for delivery due to its limited battery life (Sawadsitang et al., 2018). Vyshnave, Elysee, Patrick and Lorie (2020) conducted a research study and investigated many other technical challenges resulting from drone crashes and network issues (Jeyabalan et al., 2020). From the researcher's point of view, drones' limited battery life and load capacity inhabit their capability to make multiple transportations at once and cover long distances.

\subsubsection{Legislation challenges that drone delivery may face}

The second major challenge is the legislation challenges. According to several previous studies, legislation challenges involve government limitations and the delivery of illegal drugs (Alwateer and Loke, 2020; Stolaroff et al., 2018; Lai, Liu and Tsay, 2020). According to Oman Civil Aviation (2020), the Civil Aviation in Oman limited drones. Operators require licenses and permits from Civil Aviation to allow them to use drones. However, maximuim10,000 OMR as a fine and jail for utilising the drone without permission (Civil Aviation, 2020). Joshuah Stolaroff and other academic researchers specialising in geological engineering stated that commercial drones recently are limited in the United States and other countries worldwide. They added that the $\mathrm{EASA}^{7}$ and the $\mathrm{FAA}^{8}$ are developing regulations and laws to allow the use of commercial drones (Stolaroff et al., 2018). Mei Lai, Dan Liu, Wu Tsay from the Fuzhou University of International Trade in China mentioned no special applicable regulations and laws for commercial drones in China. The entry 
of drones into the trade field will challenge drone operators (Lai, Liu and Tsay, 2020). The other issue which comes under legislation challenges is the delivery of illegal drugs. Several recent studies confirmed that several sellers utilise a drone to deliver cocaine during the COVID-19 lockdown in the United Kingdom (Das, Mohanta and Jena, 2020; Alsamhi et al., 2021). From the researcher's perspective, FAA and countries'governments set laws and policies applicable to supervise drones' operators under the promise of respecting their health, lives and rights. The researcher agrees with the idea of applying clear government regulatory policies to fight against coronavirus.

\subsubsection{Safety and privacy challenges that drone delivery may face}

The third prime challenge is safety and privacy challenges. Majed Alwateer and Seng Loke, who are specialised in Information technology, hypothesise in their research article that drones utilised to enhance public and private safety and security levels, but drones exposed to many safety and privacy challenges. These issues related to drones' control and information about stakeholders, clients or service providers (Alwateer and Loke, 2020). Many current studies confirm that safety and privacy challenges could include GPS $^{1}$ jamming and hacking (Alwateer and Loke, 2020; Das, Mohanta and Jena, 2020; Chamola et al., 2020; Jeyabalan et al., 2020). Vyshnave Jeyabalan and other researchers emphasised in their research study that the increase in aircraft and areophane and the large size of some cities and villages create an issue to the GPS ${ }^{9}$ collection (Jeyabalan et al., 2020). This issue leads to GPS problems. The hacking issue is one of the securities and safety risks posed by drones. Majed Alwateer and Seng Loke confirmed in their research that hackers could control drones operated by the service providers and utilise a drone for unintended purposes (Alwateer and Loke, 2020). From the researcher's point of view, when drones' users give their confidential information such as account number, name, and location, hackers can attack it. They should maintain their privacy.

\subsubsection{Other challenges that drone delivery may face}

Weather conditions can be another challenge that drone delivery may face during the COVID-19 pandemic. Vyshnave Jeyabalan and other researchers assert that drones or UAVs cannot be operated in certain weather conditions such as thunderstorms and severe wind (Jeyabalan et al., 2020). According to UNICEF recent article, the lack of understanding of drones' use in such emergence cases and the insufficient support system for drones can be another challenge that drone face during the coronavirus pandemic (UNICEF, 2020). A sound understanding of drone utilisation for delivery in such a situation can add value during the pandemic.

\subsection{Future of drone delivery services in Oman post-COVID-19}

Several recent research studies estimated that commercial drone delivery would rapidly grow shortly. They also expected that with the success of drones in the logistics and transportation aspect, drone delivery would improve soon to be time-sensitive, more critical and larger payloads (Frachtenberg, 2019; Huang and Savkin, 2020). According to the ITF article, drones or UAVs prove themselves practical and versatile tools during and post COVID-19 pandemic. It states that the application of drones in the coronavirus crisis offers a learning opportunity for how to utilise drones for delivery in such emergency cases in the future. It also estimates that the airspace regulation will be updated to facilitate drones for delivery in future emergencies (OECD, 2020).

On the other hand, Michael Nentwich and Delila Horvath, who are specialised in science and technology studies, stated that there is a prospective impact of employing drones for transportation purposes in the future. They hypothesised that the potential impact could be on the job market. The growth of drone utilisation in future may lead to a shrink in the 
employment of delivery drivers (Nentwich and Horváth, 2018). The researcher strongly agrees that states drones or UAVs are a promising modality to reshape the future of the delivery system, whether in Oman or other countries. Thus, it is attracting the attention of researchers and industrial practitioners.

\subsection{1 drone delivery in future}

Various researchers conducted statistics regarding drone delivery in the future. According to Mei Lai, Dan Liu, Wu Tsay, due to expanding the e-commerce market, the annual parcel volume delivered via drone will be doubled to reach 25 billion in the USA in the next ten years (Lai, Liu and Tsay, 2020). Gino Brunner and other researchers from the computer engineering and network laboratory at ETH Zurich ${ }^{10}$ predicted that self-driving, including drones, would soon transport 80 per cent of parcels (Brunner et al., 2019). Thus, drone delivery can be profitable and feasible. Hong Jiang and Xinhui Ren, who are specialised in economic and management at the Civil Aviation University of China, estimated that by 2050, the number of drones utilised in Urban delivery would reach 1 million (Jiang and Ren, 2020). The researcher predicts that the drone may fly directly from the retailer's warehouse to the consumer's door shortly.

\subsubsection{The opportunity of drone delivery to serve various aspects in future}

Eitan Frachtenberg, a computer science professor at Reed College, assumed that drones would employ several aspects soon (Frachtenberg, 2019). The first aspect is merchandise delivery. Eitan Frachtenberg believes that merchandise delivery is one of the cores uses cases for drone delivery. He expected that Walmart might utilise drones in its extensive network, which can deliver commodities to approximately 90 per cent of Americans via drones (Frachtenberg, 2019). The second aspect is the courier delivery. Eitan Frachtenberg postulated that various companies might use drones to deliver couriers between two private parties (Frachtenberg, 2019). The third aspect that will use the drone for delivery in the future is food. Due to the time-sensitivity, drones would be applicable to deliver perishable cargo and floral. Eitan Frachtenberg estimated that with the utilisation of drones to deliver food in the future, the food market would grow globally to reach more than $\$ 160$ billion by 2023 (Frachtenberg, 2019). Another aspect that will particularly suit drone delivery is humanitarian aid. Professor Eitan Frachtenberg (2019) predicted that drone delivery applications in the humanitarian assistance industry include delivering supplies to people in war or disaster areas and transporting medical supplies post-COVID-19 crisis (Frachtenberg, 2019).

Similarly, passenger delivery could take advantage of drone delivery in the far future. Jinsoo and other researchers alluded in their journal article that Uber company collaborated with aviation companies such as Pipistrel to develop short-range and autonomous drones for delivering passengers in the future (Hwang, Kim and Kim, 2020). According to Mohamed Ferrag and Leandros Maglaras, who are specialised in computer sciences mentioned in their journal article that DHL, UPS and Amazon, which are the world's leading logistics company currently launched a new service call the drone-based delivery system. They assumed that this system would be used for rural delivery and urban first and last-mile delivery (Ferrag and Maglaras, 2019). From the researcher's perspective, the drone-based delivery system aims to modernise the delivery system shortly.

\section{Methodology}

The methodology chapter is one of the most substantial chapters in research. Research methodology is specified techniques or approaches used to determine, identify, analyse and process data regarding the research topic. It allows the readers to evaluate the study's reliability and validity critically. In this chapter, the researcher elucidates the mechanism used to illustrate actions taken to answer research questions, 
investigate the research problem and fills the research gap. The methodology chapter presents the result from the information obtained during the study period. It is done by applying procedures and approaches to meet and understand research objectives. In the methodology part, the researcher would discuss the methodological flow that answers research questions.

\subsection{Research approach}

The researcher decided to use the inductive mechanism because it does not follow any hypotheses which fitted the research study. According to Theophilus Azungah, a lecturer at Bolgatanga Polytechnic in Ghana (2018), the inductive approach generates new theory emerging from the information and learning from various experiences. Moreover, it helps the researcher establish an apparent link between the summary findings and the research objectives (Azungah, 2018). The researcher selected a qualitative method to be conducted where the narrative approach will be used in this research. Qualitative research focuses on obtaining information via informal and openended communication where it stems from the human's experiences. The bright side of using the qualitative method is that it is a flexible mechanism, allowing collecting detailedorientated data and understanding attitudes. It also enables the researcher to investigate methodology with more accuracy. The descriptive data collection is written in the research study (Huang, 2019). The researcher strongly agrees that the qualitative approach provides information experienced by specialists, which added value to the research study. On the other hand, the qualitative technique offers linguistic information where it is complicated to compare across respondents who have various regarding the drone delivery challenges during COVID-19 and the future of drone post the COVID-19 era.

The researcher decides to conduct a semistructured interview. The semi-structured interview helps the researcher to provide comparable and reliable qualitative data. Besides, it allows the researcher to gather information from the interviewees' perspective, where various ideas will be argued later in the next stage. The semi-structured interview enables the research to ask open-ended questions that allow the discussion and accurate data (DeJonckheere and Vaughn, 2019). Due to coronavirus outbreaks nowadays, the researcher prefers to conduct an online interview via Microsoft teams, Google meet and Zoom. Through conducting an online- interview, the researcher can prepare well and record the interview. From the researcher perspective, conducting the online interview is fixable and cost-saving. The gathered data expects to demonstrate the efficiency of drone delivery services in Oman during the coronavirus outbreak. Besides, the research aims to determine the challenges that commercial drones face in Oman in the era of the COVID19 pandemic. The study also seeks to estimate the future of drone delivery in Oman posts the COVID-19 crisis.

\subsection{Research design}

The researcher employed a qualitative approach to gather the data from respondents regarding the efficiency of drone delivery services in Oman. The researcher decided to conduct a semi-structured interview with an expert from various logistics and transportation companies in Oman. The probability sampling technique with a random selection from the targeted respondents will be used in this research study. Under the probability sampling mechanism, the researcher would prefer to use simple random sampling. Hence, this research study employed a qualitative research design to agree on the efficiency of drone delivery service in Oman during and post the coronavirus era. Patrik Aspers and Ugo Corte mentioned that qualitative research focuses on gathering and analysing non-numerical data to understand ideas, concepts or experiences. They said that this type of research design allows the researcher to collect in-depth information and generate new ideas into the research study (Aspers and Corte, 2019). Since it is a communicative approach, respondents can build their trust in the researcher where the information obtained is primary and unadulterated. Besides, the qualitative research 
method works to solve complicated issues by dividing them into meaningful inferences that are simply understood and readable (Canyon Hydro et al., 2013).

\subsection{Population and sample size}

The study population consists of logistics and transport institutes' employees in Oman as there is more representative of the logistics industry. The people of data is from transport companies, airports, seaports and logistics organisations. The researcher selects the respondents from the high positions because they are certified and accessible employees who could provide valid input to the research regarding the efficiency of drone delivery service in Oman during and after the coronavirus pandemic. The researcher planned to meet ten interviewees from several logistics and transport industries in Oman. Due to the outbreak of the coronavirus pandemic in Oman, the researcher prefers to conduct the interviews online with all respondents. The researcher expects $85 \%$ of respondents will give perspectives and ideas regarding the efficiency of drone delivery services in Oman. The researcher will ask for permits from the interviewees to record the interviews. The researcher will use simple random sampling to pick out the interviewees. The researcher uses this technique to ensure that each population members get an equal chance for the selection or the opportunity of getting responses.

\subsection{Data collection}

Data collection is a systematic process for gathering observations or measurements. The data collection allows the researcher to obtain initial-hand knowledge and primer insight into the research issue. The researcher uses primary and secondary data collection methods for the research study. Those data collection methods will show various experts and respondents' expectations and ideas regarding the efficiency of drone delivery services in Oman during and after the coronavirus crisis. The researcher aims to answer the study questions and collect valid and reliable information using primary and secondary data collection techniques.

\subsubsection{Primary data collection sources}

The researcher decided to use a qualitative method as a primary data source for the entire research study. For this research, the researcher will conduct interviews, a loosely structured qualitative interview with people who know about the topic of the study. The semistructured interview allows the researcher to ask questions, seek new insights and assess phenomena from several perspectives (Aspers and Corte, 2019). It also allows the researcher to learn in-depth about the efficiency of drone delivery services in Oman during and post the COVID-19 era. Using the interview as a primary data collection source allows the respondents to raise valuable data and problems that the interviewer may not expect.

\subsubsection{Secondary data collection sources}

The secondary data collection source refers to the information collected by someone else other than the researcher. It provides insights into the research field of the recent state-of-the-art approach. The secondary data collection source also creates a kind of research gap that the research must fill. This type of data collection could be external and internal data sources of information that may cover a wide range of study fields (Aspers and Corte, 2019). The researcher conducts the literature review as a secondary data collection source via using several database sources. The search strategy of the literature review focused on academic articles, journal articles and books. Before the screening, the researcher reviewed a sample of more than 400 academic articles, journal articles, books, reports and websites to determine whether to include them for further review or reject them.

\section{Findings and analysis}

Chapter four will present the analysis and the findings inferred from the semi-structured interviews with several respondents. The outcomes linked with the research questions, which guided the whole research. This part of the research study solely focuses on earnestly 
gathering data. The collected data produced by the initial qualitative analysis to facilitate the argumentation. The researcher uses primary and secondary data to answer the research questions and achieve its objectives. The chapter analyses the information to characterise, identify and figure out the efficiency of drone delivery services and the challenges that drones may face in Oman during the coronavirus outbreak. Besides, the researcher will determine the suggestions which aim to better the drone delivery services in Oman shortly in chapter five at a later stage.

The gathered data from the conducted interviews analysed using descriptive tools. The descriptive tools enable the researcher to describe the collected information in charts. The researcher decided to divide the finding and analysis chapter into four themes. The four themes are the performance of drone delivery services in Oman, the efficiency of drone delivery services in Oman during the coronavirus pandemic, the challenges that drones may face during the COVID-19 and the prediction of drone delivery services future in Oman. Charts, figures and tables will be used to facilitate it for the reader to understand.

As previously mentioned, the researcher set several questions to advance the information collected through the interviews. The main question explores the drone's performance in Oman as an alternative modality to transport goods. The following are a reminder of the research sub-question:

1. How efficient are drones' delivery services in Oman during the COVID19 ?

2. What are the challenges of implementing drones' delivery services in Oman during the COVID-19?

3. What is the future of drones' delivery in Oman post the COVID-19?

\subsection{Methods of analysing and presenting data}

The researcher gathered data and various ideas from interviews with several specialists from different transport and logistics industries. The data analysis methods will help the researcher to assess information quality and analysing data. The researcher applied a descriptive statistical analysis approach to recogniseOman's frequent ideas and drone delivery service performance for this research study. Besides, the researcher used tables and charts to analyse the collected data from the interviews.

\subsection{Discussion of findings 4.2.1 Data description}

The interviews result from different respondents presented and analysed in this chapter based on drone delivery services scenarios. The interview questions encompass both sides; the efficiency of drone delivery services in Oman during the coronavirus outbreak and the challenges that drones may face during the COVID-19 crisis. Besides, the interview questions comprehend respondents'predictions regarding the efficiency of drone delivery services in Oman post the coronavirus pandemic. The interview questions can be found in appendix 1 .

\subsubsection{The performance of drone delivery services in Oman}

Currently, drones become an alternative modality for transporting parcels and other goods. Most of the participants agree that drones are efficient means of delivery. Speaker 2 said that "in the world, drones are a very effective method for delivering goods especially parcels and small cargo". Besides, speaker 3 added that a drone is an efficient means of delivery if the drone equipped with the correct navigation devices and the quorum of the air administration is complete. As declared by speaker 8 , the drone is an effective and positive solution for conveying goods to customers'doors.

On the other hand, speaker 5 argues that "in general, drones can be an efficient means of delivery, but it needs further improvement to be relied upon in conveying goods". Speaker 4 disputes that drone is still not an efficient delivery method as it is costly and short distances. He added that using land means to 
deliver goods is better than drones, but the drone can be an efficient means for transportation services in the future.

The researcher asked the interviewees about their thought regarding the performance of drone delivery services in Oman. The interviewees had different opinions. Speaker 1 agrees that the performance of drone delivery services is good where there are real successful experiments were done for delivering parcels via drones in Oman. Speaker 9 added that drones used in Oman for delivering packages in some remote areas. She said that an experiment was done to deliver goods via drone from Jalan to Wadi Bani Khalid. She declared that it was a very effective and successful drone delivery test. Besides, interviewee 3 argued that he is neutral where previously they had tested drones, which was quite successful. He mentioned in the interview that an experiment could be done for delivering goods to Jabal Akdar and Jabal Shams. Another judgment raised by speaker five where she disagrees with the question that asked by the researcher. She said that "in Oman, we are still new in applying drones". In addition, speaker 7 disagree that drone delivery in Oman is good. He declared that Oman still at the beginning where there are challenges, and success requires patience.

\subsubsection{The efficiency of drone delivery services in Oman during the COVID-19 pandemic}

To answer the first research sub-questions, the researcher asked the interviewees to give their opinions about the growth of drone delivery services in Oman considering the coronavirus outbreak. The researcher received various perspectives where speaker 2, speaker 3, speaker 6 and speaker 8 agree. Interviewee 6 said that considering the coronavirus pandemic, many countries such as Oman start to use the drone to deliver goods whether to testing or using it as an alternative means of transportation. According to speaker 8, the successful experiments are done by ASYAD is a good indicator for using the drone as a delivery means during the COVID-19 in Oman soon. Speaker 9 said, "if drone applied in logistics during coronavirus in Oman, it would be a very effective modality". He added that they try to reduce the number of employees working in the logistics sector considering the COVID-19. Applying drones will inevitably be an efficient means for delivery and minimise human interaction. Interviewee 1 argued that the use of drones for delivery only experiences. He added that some of them could be applied soon, especially in remoteareas.

Nevertheless, interviewee 5, interviewee 10, interviewee 7 and interviewee 9 disagree with the idea, stating that drone delivery services have grown in Oman during the coronavirus crisis. Speaker 10 argued that drones used in many ways during the COVID-19, such as aerial spraying and public space monitoring during the lockdown and quarantine. She highlighted that drone is still not applied in Oman's transportation aspect, where she wished that Oman relies on the drone for delivery services during the COVID-19 as quick as possible.

In the interview, the researcher asked the participants to rate the efficiency of drone delivery services in Oman during the coronavirus pandemic based on the experiments. The following charts summarise their point of view.

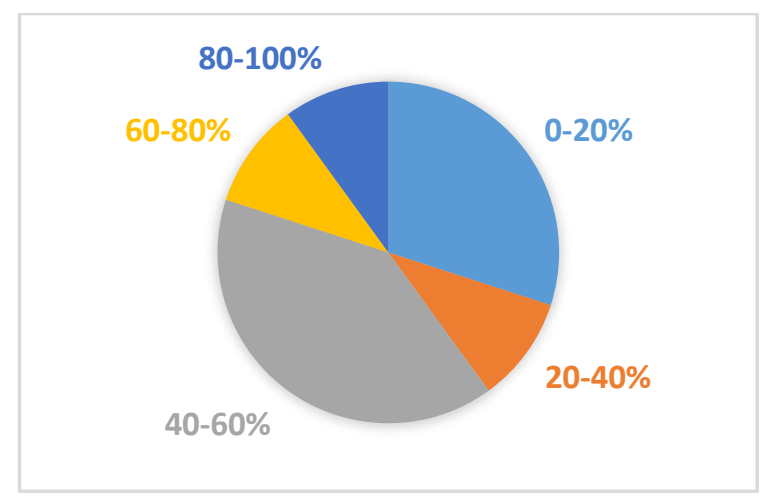

Figure 1; Rating the Efficiency of

Drone Delivery Services in Oman

During The COVID-19 
As illustrated, the figure shows participants'ratings regarding the efficiency of drone delivery services in Oman during the COVID-19 crisis. It is described that most respondents rate the efficiency of drone delivery services in Oman above $40 \%$. Four of the interviewees rated the drone delivery efficiency between 40-60\%. Three participants said that the drone delivery services in Oman during the coronavirus outbreak are efficient, from 0 up to $20 \%$.

Another question was asked related to the most sectorsthat use the drone for delivery in Oman during the COVID-19 crisis. The interviewees have different perspectives, which described in the below chart.

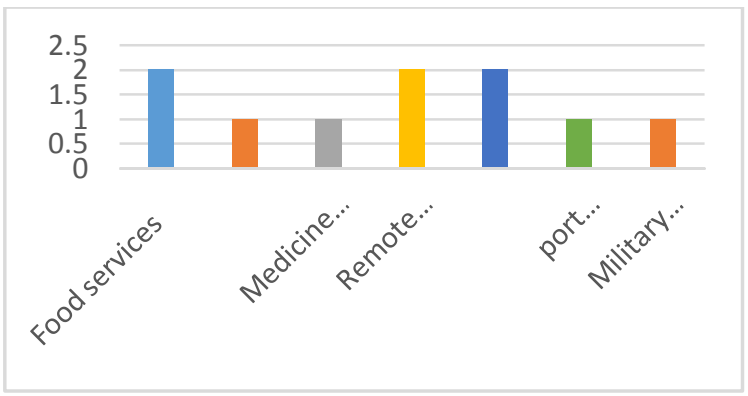

Figure 2; The Most Sector Use

\section{Drone for Delivery in Oman During The COVID-19}

As the chart show, two interviewees agree that food services are the most used sector for delivery in Oman. Speaker 8 declared that some restaurants might benefit from this means of delivery during the quarantine. Whilst two other participants, who are interviewees 3 and 5, said that remote area delivery services are the most aspect of the use drone for transportation purposes as it is an unreachable area. Speakers 7 and 8 stated that the most part utilisesdrones for delivery in Oman during the coronavirus is a dangerous area. Speaker 1 declared that the military sector is the most used drone for delivery. The other respondents argued that other sectors are mainly used a drone for transportation purposes such as education, medicine and port delivery services.

\subsubsection{Challenges that drone delivery may face in Oman during the COVID-19}

Despite the benefits of drones in response to the coronavirus pandemic, the utilisation of drones in Oman faces some challenges and limitations. The researcher asked participants to list challenges that drone delivery may face during the COVID-19 in Oman in the conducted interviews. The following table summarises interviewees' opinions.

Table 1; Challenges That Drone

\section{Delivery Services May Face in}

\section{Oman During Coronavirus}

\begin{tabular}{|c|c|}
\hline Interviewees & Challenges drones may face \\
\hline Speaker 1 & $\begin{array}{l}\text { - Government } \\
\text { limitations. } \\
\text { - } \quad \text { Privacy challenge. }\end{array}$ \\
\hline Speaker 2 & $\begin{array}{l}\text { - Limited payload } \\
\text { capacity. } \\
\text { - } \quad \text { Not applicable for } \\
\text { long distances. } \\
\text { - Safety and privacy } \\
\text { challenges. }\end{array}$ \\
\hline Speaker 3 & $\begin{array}{l}\text { - Short battery life. } \\
\text { Lack of } \\
\text { communication with } \\
\text { drones. }\end{array}$ \\
\hline Speaker 4 & $\begin{array}{l}\text { - Legislation } \\
\text { challenges. } \\
\text { - Safety and privacy } \\
\text { challenges. }\end{array}$ \\
\hline Speaker 5 & $\begin{array}{l}\text { - } \text { Technical challenges } \\
\text { - Oman regulations } \\
\text { limitation. } \\
\text { - } \quad \text { Privacy issue. }\end{array}$ \\
\hline Speaker 6 & $\begin{array}{l}\text { - Low loading capacity. } \\
\text { - Low battery power. } \\
\text { - Takeoff and landing } \\
\text { challenges. }\end{array}$ \\
\hline
\end{tabular}




\begin{tabular}{|c|c|}
\hline Speaker 7 & $\begin{array}{l}\text { - Legislation limitation } \\
\text { challenge. } \\
\text { - Terrain avoidance } \\
\text { issue. }\end{array}$ \\
\hline Speaker 8 & $\begin{array}{l}\text { - Government } \\
\text { limitation. } \\
\text { - } \quad \text { Technical problems. } \\
\text { - } \text { Compliances of } \\
\text { people about drones' } \\
\text { flight on their house. } \\
\text { - Route planning } \\
\text { problems. }\end{array}$ \\
\hline Speaker 9 & $\begin{array}{l}\text { - Safety problems. } \\
\text { - } \quad \text { Low capacity. } \\
\text { - Government } \\
\text { restrictions } \\
\text { challenge. }\end{array}$ \\
\hline Speaker 10 & $\begin{array}{l}\text { - Government } \\
\text { limitations. } \\
\text { - Costly. }\end{array}$ \\
\hline
\end{tabular}

Speaker 1 declared that the drone in Oman require permits from the Civil Aviation Authority, where the drone operators need to fill form including the reason for using the drone and for which type of business. Interviewee 2 added that one of the challenges that drones may face in Oman is safety and privacy issues. He justified that they closed the Muscat airport tarmac because the air traffic controller saw a drone flying there, and they stopped the operation there. He added that this safety issue leads to delay flight times. Besides, speaker 3 stated that the inability of the control tower to communicate with drones to prevent collision and give direction is another challenge that drones may face in Oman. He said that this challenge is appeared in Oman due to the novelty of the drone field. Speaker 7 presented another challenge drone in Oman may face, which is the terrain avoidance issue. He said that drone operators might face obstacles to inform drones about the terrains such as mountains, electrical pylons or tall trees. He stated that drone operators might lose drone control where the drone may crash. According to speaker 10, the high cost of drones is another major challenge that may face. She said that drones are costly in terms of their maintenance if they break down, employees' training and more.

Under this section, the research asked the interviewees another question related to Oman's government limitation challenges in such emergency circumstances. In line with interviews data, $80 \%$ of participants agree that Oman's government regulation could limit commercial drones in such emergencies. Most of the speakers confirmed that commercial drones in Oman require approvals and permission from several government institutes, including the Royal Oman Police, the Civil Aviation Authority and the Ministry of Environment.

\subsubsection{The future of drone delivery services posts the COVID-19}

One of the researcher's goals from conducting interviews is to collect participants' expectations regarding drone delivery services in Oman after the coronavirus. The researcher asked interviewees a question related to the possibility of Oman learning from the other countries' experiences for how they utilisedrones in such emergency cases. All participants agree that Oman could learn from others' tests to deal with such emergency circumstances. Speaker 2 said that he does not see any objection to understand from neighbouring countries how they use the drone for delivering goods during the COVID-19 crisis. Whilst interviewee 3 stated that he hopes that investors and companies in Oman will implement drones for delivery by learning from other countries, they employ drones in the transportation industry. He declared that as Civil Aviation Authority, they are ready to contribute to facilitating licensing procedures. Speaker 8 added that, undoubtedly, Oman could learn from how China uses drones to deliver food and medicine supplies to Oman for a remote area in such emergencies.

The researcher asked another question related to the growth of the drone delivery industry in 
Oman in the future. All interviewees concur that using drones for commercial purposes will be a new industry in Oman soon. Speaker 4 expected that the drone industry would increase, especially the technological progress globally, and the revolution encourages the growth of such technology. Speaker 10 added that she estimated that the drone market would grow in Oman by the near future, and it could be an additional means of transportation. Besides, interviewee 6 stated that the drone industry would rapidly increase in Oman by the near future, especially in conveying restaurant orders and medicines. He expected the growth of the drone market soon. It could be used in delivering necessities to remote and rural areas.

In the interview, the researcher asked the interviewees to rate the drone delivery services in Oman post the coronavirus. The following figure epitomises their perspectives.

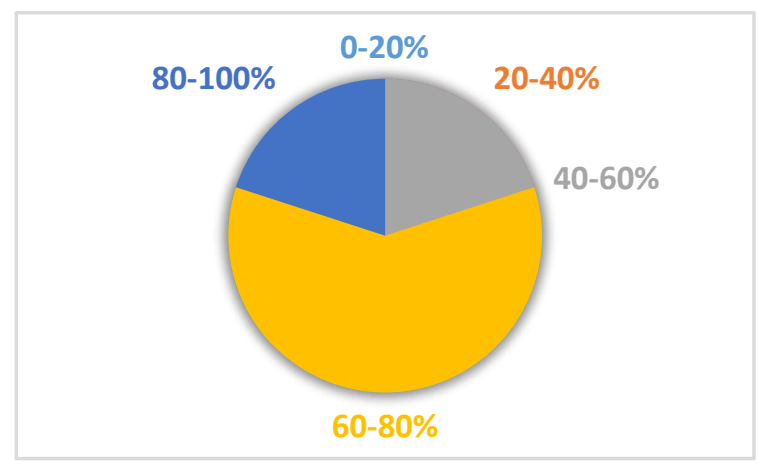

Figure 3; Rating the Drone

\section{Delivery Services in Oman Post The COVID-19}

The above figure presents the rating of interviewees regarding the drone delivery services in Oman post the coronavirus era. It is demonstrated that most of the participants rate the drone delivery services in Oman post the COVID-19 between $60 \%$ to $80 \%$. Two of the interviewees rated the performance of drone delivery after the coronavirus era above $80 \%$. Whilst two of them rated the performance of commercial drones in the transportation aspect from $20 \%$ up to $40 \%$. Speaker 4 said that it might be early to speak about it. Still, he supposed it might take two to five years to develop, considering that not many companies or investors adopted drone technology in Oman for delivery as a means of transportation.

Another question was asked in the interview, which is related to the sectors in Oman that could utilise a commercial drone for transportation post the coronavirus pandemic. The participants have various points of view, which is presented in the following chart.

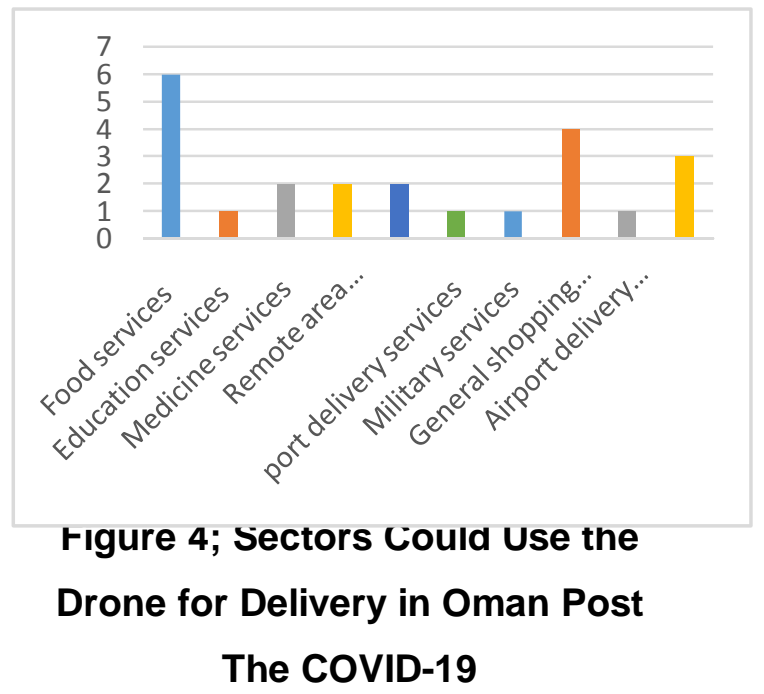

As the chart above shows, food delivery services are the most selected sector which could use the drone as a mean of delivery in the future as participants expected. Several interviewees estimated that general shopping services and courier delivery services are two of the most services that could utilise commercial drones for delivering mails and orders soon. Some of them expected that drone delivery services could be used in healthcare, remote area delivery, and dangerous area delivery. Few interviewees said that drones could be used in education, port, airport, and military aspects.

To develop the drone delivery services industry in the future and build smart cities, the researcher asked the interviewees to give their suggestions to better the drone delivery services in Oman. The below table summarises the direction of each participant to enhance drone delivery services in Oman. 
Table 2; Suggestions to Better

\section{the Drone Delivery Services in}

Oman in Future

\begin{tabular}{|c|c|}
\hline Participants & Suggestions \\
\hline Speaker 1 & $\begin{array}{l}\text { - Use drones in } \\
\text { delivering medicine and } \\
\text { other supplies. }\end{array}$ \\
\hline Speaker 2 & $\begin{array}{l}\text { - Apply drone delivery } \\
\text { software. }\end{array}$ \\
\hline Speaker 3 & $\begin{array}{l}\text { use this technology in } \\
\text { restaurants to deliver } \\
\text { food and deliver } \\
\text { parcels to } \\
\text { customer'sdoors, which } \\
\text { will save time in both } \\
\text { deliveries. }\end{array}$ \\
\hline Speaker 4 & $\begin{array}{l}\text { Use a system called } \\
\text { UTM (Unmanned } \\
\text { Traffic Management). }\end{array}$ \\
\hline Speaker 5 & $\begin{array}{l}\text { - Have a more robust } \\
\text { structure. } \\
\text { - Use drone in } \\
\text { warehouse } \\
\text { management. }\end{array}$ \\
\hline Speaker 6 & $\begin{array}{l}\text { Facilitate the } \\
\text { procedures of permits } \\
\text { to engage the } \\
\text { merchants and } \\
\text { enhance the usage of } \\
\text { this mean. }\end{array}$ \\
\hline Speaker 7 & $\begin{array}{l}\text { learn from the other } \\
\text { countries how to use } \\
\text { this kind of services in } \\
\text { such these difficult }\end{array}$ \\
\hline
\end{tabular}

\begin{tabular}{|l|l|}
\hline & \multicolumn{1}{|l|}{ times. } \\
\hline Speaker 8 & $\begin{array}{l}\text { Use drones in express } \\
\text { shipping and postal } \\
\text { delivery. }\end{array}$ \\
\hline Speaker 9 & $\bullet \quad \begin{array}{l}\text { Define new and old } \\
\text { companies with this } \\
\text { technology. }\end{array}$ \\
\hline Speaker 10 & $\bullet \quad \begin{array}{l}\text { Use a drone to deliver } \\
\text { parcels for remoting } \\
\text { areas. }\end{array}$ \\
& $\begin{array}{l}\text { Make the process of } \\
\text { drone registrations and } \\
\text { permission smooth. }\end{array}$ \\
\hline
\end{tabular}

The findings presented that Oman still does not apply drones to deliver as they are now doing tests. The result indicates that Oman could use the drone as an additional means of delivery soon with the successful drone delivery services experiments and tests. The findings match with literature review theory which stated some companies in Oman did an investigation for testing drone delivery services in Oman during the coronavirus era. The finding outcome presented several challenges commercial drones may face in Oman, such as technical issues, government limitations, and safety and privacy challenges. The previous research studies focused on the same challenges that provided in the finding part.

Regarding the future of drone delivery services in Oman, the analysis shows that drone delivery services could increase rapidly in Oman, and it could be applied in several aspects. In line with the literature review data, several previous pieces of research predicted that drones would be used for delivery purposes in many factors such as medicines, food and courier by the near future. This data corresponds to the finding result. 


\section{Conclusion and recommendations}

Based on the data analysis in the previous chapter, this chapter concludes the findings' part and suggests recommendations to better drone delivery services in Oman post the coronavirus pandemic.

\subsection{Conclusion}

Through the analysis in the previous chapter, the research found that drones' delivery services are an effective means of transportation around the globe. Due to the drone industry's novelty, Oman is still new in applying commercial drones for delivery purposes. Based on the analysis in chapter four, during the COVID-19 crisis, Oman started to test drones to convey parcels for different remote areas such as Wadi Bani Khalid. The experiments were all successful and beneficial. So, the drone still not applied in Oman as an alternative means of delivery. According to the preceding analysis, drones in Oman during the coronavirus face several limitations and challenges such as government limitations, technical challenges, privacy challenges, and safety challenges. In line with the analysis and findings data, Oman's government could limit commercial drones as it requires several approvals and permits from different institutes.

Regarding the future of drone delivery services posts the COVID-19, the retail drone industry could grow soon. It is expected to be an additional means of transportation, especially for conveying parcels, restaurant orders, and courier deliveries. Commonly, the value of this research paper relies on reaching a higher level of drone delivery services performance in Oman by finding the most suitable approaches.

After recapping the interpretations and findings in the previous chapter, the researcher states recommendations in the following few lines.

\subsection{Research Implications}

The researchershas many implications for managerial or practitioners, beside the theoretical implications.

\section{Practical implications}

- Diversifying the use of drone delivery services to cover several aspects. Oman could utilise a drone to transport restaurant orders to customers' doors, especially in civilised cities, which leads to a short delivery time from 30 minutes to less than 10 minutes. Besides, the drones could be applied in conveying medicines supplies from central hospitals to health complexes within the city and vice versa. Furthermore, Oman could use commercial drones in the courier aspect to deliver mails and parcels to customers' doors via drones.

- Applying Drone Delivery Software (DDS). This software enables drone operators to manage and deploy a fleet of drones via $4 \mathrm{G}$ could connectivity which help the drone operators to real-time flight data and control drone from a remote place. Via applying DDS, the drones can automatically make optimised routes for no-fly zones and terrains avoidance. Using DDS also helps to precisely landing and transporting parcels safely through the deployed tags on the targeted locations. Thus, the transportation costs will be minimised.

- Implementing a UTM system could better drone delivery services in Oman soon. The UTM system or Unmanned Traffic Management system would help to control the drone paths in the sky. By the sensors and cameras connected with the system, drones would identify a nearby object and take responsive action to avoid it. Via applying UTM systems, the drone could control its speed automatically. The GPS systems in the UTM program guide the drones in delivering packages to the customers'doors. 
- Using drone delivery services in a remote area would be a great addition. Due to the difficulties in reaching the remote site, the drone could be an excellent solution to deliver goods for rural areas such as Al-Jabal Al-Akhdar, Jabal Shams and Wakan village.

- Using buildings' rooftops for drone parcel delivery. This idea could reduce the delivery time and takeoff and landing problem.

\section{Theoretical Implications}

From the findings and interviews with professional still the area of delivery via drone needs more stress from academician,the study found that the adoption, cost and efficiency slowing down the adoption because of lack of evidence on the efficiency and suitability of this service in oman, these factor have to be proved by research and investigation. Also the regulations related to drone and the awareness of the regulation is still area of research and investigation.

\section{Research limitation}

This study has some limitations that should be noted.firstly: the study was crossectional and Time limitation is the other limitation that needs to be highlighted. Secondly the sample size and the practitioners experience and response.

\subsubsection{Directions for Future research}

More researchis needed in this domain. The researcher recommends the new researcher following suggestions for future research.

- Studying the future of drone delivery services in Oman

- Exploring the application of drone delivery services in different aspectsin Oman during the coronavirus crisis.

- Studying drone's ability as delivery services to apply in another supply chain part including warehouse, distribution centre and manufacture.

\section{Appendices}

Appendix 1; Interview questions link

https://forms.office.com/Pages/ResponsePage.a spx?id=PahWpA0mkaK26N 479WhseNvozb2JhDltBiQfzcQ L1UM01WOUpXMUhNWEpVNjhPOEdYSU 5DWjYyVC4u

\section{References}

Akanbi, O., Amiri, I. and Kordi, E. (2015) 'Chapter 3 - Research Methodology', in A Machine-Learning Approach to Phishing Detection and Defense, pp. 35-43. DOI: 10.1016/B978-0-12-802927-5/00003-4.

Alghaithi, R. (2021) Research Framework, Creately.

Alsamhi, S. H. et al.(2021) 'Blockchain for Decentralized Multi-Drone to Combat COVID19', Transactions on Emerging Telecommunication Technologies.

Alwateer, M. and Loke, S. W. (2020) 'Emerging Drone Services', (SEPTEMBER), pp. 47-51.

Aspers, P. and Corte, U. (2019) 'What is Qualitative in Qualitative Research, Qualitative Sociology, 42(2), pp. 139-160. DOI: 10.1007/s11133-019-9413-7.

ASYAD (2020) Oman Logistics Centre conduct parcel delivery and inventory counting experiment using drones. Available at: https://www.asyad.om/mediacenter/news/2020/04/07/oman-logistics-centreconducts-parcel-delivery-and-inventorycounting-experiment-using-drones (Accessed: 1 December 2020).

Azungah, T. (2018) 'Qualitative research: 
deductive and inductive approaches to data analysis, Qualitative Research Journal, 18(4), pp. 383-400. DOI: 10.1108/QRJ-D-18-00035.

Brunner, G. et al. (2019) 'The urban last-mile problem: Autonomous drone delivery to your balcony', 2019 International Conference on Unmanned Aircraft Systems, ICUAS 2019, pp. 1005-1012.

DOI: 10.1109/ICUAS.2019.8798337.

Canyon Hydro et al. (2013) 'We are IntechOpen, the world s leading publisher of Open Access books built by scientists, for scientists TOP $1 \%$ ', Intech, 32(July), pp. 137144. Available at: http://www.intechopen.com/books/trends-intelecommunications-technologies/gps-totalelectron-content-tec- prediction-at-ionospherelayer-over-the-equatorial-

region\%0AInTec\%0Ahttp://www.asociatiamhc. ro/wp-content/uploads/2013/11/Guide-toHydropower.pdf.

Chamola, V. et al. (2020) 'A Comprehensive Review of the COVID-19 Pandemic and the Role of IoT, Drones, AI, Blockchain, and 5G in Managing its Impact', IEEE Access, 8(April), pp. 90225-90265. DOI: 10.1109/ACCESS.2020.2992341.

Civil Aviation (2020) 'CAR-102 Civil Aviation Regulation Remote Piloted Aircraft', (October).

Das, S., Mohanta, B. K. and Jena, D. (2020) 'IoT Commercial Drone and Its Privacy and Security Issues', 2020 International Conference on Computer Science, Engineering and Applications, ICCSEA 2020, pp. 4-7. DOI: 10.1109/ICCSEA49143.2020.9132958.

DeJonckheere, M. and Vaughn, L. M. (2019) 'Semistructured interviewing in primary care research: A balance of relationship and rigour', Family Medicine and Community Health, 7(2), pp. 1-8. DOI: 10.1136/fmch-2018-000057.

EUCHI, J. (2020) 'Do drones have a realistic place in a pandemic fight for delivering medical supplies in healthcare systems problems?', Chinese Journal of Aeronautics. DOI: 10.1016/j.cja.2020.06.006.

Ferrag, M. A. and Maglaras, L. (2019)
'Deliverycoin: An IDS and blockchain-based delivery framework for drone-delivered services', Computers, 8(3), pp. 1-15. DOI: 10.3390/computers8030058.

Frachtenberg, E. (2019) 'Practical Drone Delivery', Computer, 52(12), pp. 53-57. DOI: 10.1109/MC.2019.2942290.

Hii, M. S. Y., Courtney, P. and Royall, P. G. (2019) 'An evaluation of the delivery of medicines using drones', Drones, 3(3), pp. 120. DOI: 10.3390/drones3030052.

Huang, A. (2019) Advantages of Qualitative Research Methods. Available at: https://www.en.globalstatistik.com/advantagesof-qualitative-research-methods/ (Accessed: 2 April 2021).

Huang, H. and Savkin, A. V. (2020) 'A Method of Optimised Deployment of Charging Stations for Drone Delivery', IEEE Transactions on Transportation Electrification, 6(2), pp. 510 518. DOI: 10.1109/TTE.2020.2988149.

Hwang, J., Kim, D. and Kim, J. J. (2020) 'How to Form Behavioral Intentions in the Field of Drone Food Delivery Services: The Moderating Role of the COVID-19 Outbreak'.

Hwang, J., Kim, I. and Gulzar, M. A. (2020) 'Understanding the eco-friendly role of drone food delivery services: Deepening the theory of planned behaviour', Sustainability (Switzerland), 12(4), pp. 1-12. DOI: 10.3390/su12041440.

Jeyabalan, V. et al. (2020) 'Context-specific challenges, opportunities, and ethics of drones for healthcare delivery in the eyes of program managers and field staff: A multi-site qualitative study', Drones, 4(3), pp. 1-20. DOI: 10.3390/drones4030044.

Jiang, H. and Ren, X. (2020) 'Comparative Analysis of Drones and Riders in On-Demand Meal Delivery Based on Prospect Theory', Discrete Dynamics in Nature and Society, 2020. DOI: 10.1155/2020/9237689.

Lai, M. C., Liu, D. and Tsay, W. Der (2020) 'Functional Deployment of Drone Logistics', 2nd IEEE Eurasia Conference on Biomedical 
Engineering, Healthcare and Sustainability 2020, ECBIOS 2020, pp. 1-4. DOI:

10.1109/ECBIOS50299.2020.9203635.

Nentwich, M. and Horváth, D. M. (2018) 'The vision of delivery drones', TATuP - Zeitschrift für Technikfolgenabschätzung in Theorie und Praxis, 27(2), pp. 46-52. doi:

10.14512/tatup.27.2.46.

OECD (2020) 'Drones in the Era of Coronavirus', (June).

Oman Vision 2040 (2020) 'Vision Document', Supply Chain Management, pp. 1-8.

Scott, J. E. and Scott, C. H. (2018) 'Models for Drone Delivery of Medications and Other Healthcare Items', International Journal of Healthcare Information Systems and Informatics, 13(3), pp. 20-34. DOI: 10.4018/IJHISI.2018070102.

Stolaroff, J. K. et al.(2018) 'Energy use and life cycle greenhouse gas emissions of drones for commercial package delivery, Nature Communications, 9(1), pp. 1-13. DOI: 10.1038/s41467-017-02411-5.

UNICEF (2020) 'How Drones Can Be Used to combat COVID-19 How Drones Can Be Used to combat COVID-19', pp. 1-4. 